\title{
The Management of Glioblastomas during the SARS-CoV-19 Pandemic: A Narrative Overview
}

\author{
Mohamed Amine Baba ${ }^{1,2 *}$, Nawal Adali ${ }^{1,2}$
}

${ }^{1}$ Laboratory of Health Sciences Research, Ibn Zohr University, 80000 Agadir, MOROCCO

2 Faculty of Medicine and Pharmacy of Agadir, Ibn Zohr University, 80000 Agadir, MOROCCO

* Corresponding author:

babamedamine2@gmail.com

\section{EUROPEAN JOURNAL OF BASIC MEDICAL SCIENCE}

Eur J Basic Med Sci 2021;11(2):19-22

Received: 2 Dec 2020

Accepted: 18 Jan 2021

\begin{abstract}
The SARS-CoV-2 pandemic and covid-19 diffusion are an international public health emergency. Patients with a history of cancer have a higher incidence of infection with severe acute respiratory syndrome-coronavirus 2 (SARS-CoV-2) and higher risk of severe COVID-19-associated events.

Glioblastoma is considered to be among the most aggressive cancers, in this direction the value of treatment must be balanced with risks of exposure to infection, inducing immunosuppression and survival benefit. the objective of this review is to present all international consensus recommendation for the management of patients with glioblastoma (GBM) to inform clinical practice.

During this pandemic crisis, careful patient selection that balances the risks and benefits of treatment is paramount to optimize the care of patients with glioblastoma in this setting.
\end{abstract}

Keywords: Glioblastoma, COVID-19, cancer 


\section{INTRODUCTION}

The SARS-CoV-2 pandemic and covid-19 diffusion are an international public health emergency [1]. Patients with a history of cancer have a higher incidence of infection with severe acute respiratory syndromecoronavirus 2 (SARS-CoV-2) and higher risk of severe COVID-19-associated events [2]. Age is considered to be an important factor that considerably increases the risk of death linked to the Covid-19 pandemic [3, 4], it should be noted here that the incidence of glioblastoma (GBM) is increasing in the elderly population.

Consequently, this pandemic poses an imminent and extraordinary threat to many adults with glioblastoma, and also to healthcare systems.

Since neuro-oncology patients with glioblastoma are a vulnerable patient group, the value of treatment must be balanced with risks of exposure to infection, inducing immunosuppression and survival benefit.

The optimal treatment for glioblastoma (GBM) is maximal safe resection followed by concurrent chemoradiotherapy (CRT) and monthly adjuvant temozolomide (TMZ) [5, 6].

In this review, we present an international consensus recommendation for the management of patients with glioblastoma (GBM) to inform clinical practice.

\section{NEUROSURGERY TREATMENT}

The main prognostic factor for these patients' survival with GBM is the extent of resection of the tumor, and any delay in surgery may reduce the chances of successful treatment [7-10].

Given the high demand for intensive care during the pandemic, it is strongly recommended to identify patients who potentially need intensive care or a ventilator before the operation [11].

For the different surgical techniques used for glioblastoma, awake craniotomy is considered the gold standard for achieving maximum safe resection in patients with intracranial glioma.

This technique requires direct contact. between caregivers and patients during surgery, therefore, it is considered high risk during this pandemic [12].

for centers that do awake craniotomies, patients should undergo testing and isolation to confirm the absence of
COVID-19 and allow them to undergo surgery as soon as possible.

For scheduled glioma surgery, all patients in China should undergo routine presurgical evaluation and "COVID-19 screening," which includes a chest computed tomographic scan and laboratory test for the novel coronavirus [13].

\section{RADIO-CHEMOTHERAPY TREATMENT}

Several recent studies recommend that for patients with glioblastoma, urgent surgery should be performed with 1 to 2 weeks of diagnosis, followed by adjuvant chemotherapy and radiation therapy according to established standards.

Radiation oncology centers should establish protocols to limit patients in waiting areas and provide masks for patients.

In cases where hypofractionated radiotherapy could be used to limit patient exposure, this should be considered [14]. during a radiotherapy session, the recommendations emphasize the wearing of surgical masks under the thermoplastic mask and a transparent disposable packaging must be applied to the immobilization devices [15].

For chemotherapy, the addition of TMZ to the initial treatment of GBM provided an Overall Survival (OS) benefit. This benefit is more pronounced in patients with a hypermethylated MGMT promoter [16]. However, haematologic toxicities are observed in these patients. Therefore, the potential long-term benefit of OS associated with the addition of TMZ should be carefully weighed against a potential risk of serious complications upon exposure to SARS-CoV-2 infection.

As per the British Neuro-Oncology Society (BNOS), it has been suggested to consider reducing the course and fraction of radiotherapy and chemotherapy if there is no significant worse prognosis. Moreover, For MGMT unmethylated glioblastoma patients, chemotherapy may be excluded; monitor patients for any deterioration. Oral therapy regimens are preferred, if possible, instead of Intravenous administration (IV) administration [17] , however , for those patients requiring infusions, patients should be appropriately separated with masks given.

Oncology establishments must establish an emergency plan for postive cases [18], a recent review recommends for cases tested postive to Covid 19, the 
cancer treatment must be stopped until recovery and the risk-benefit ratio of the treatment must be evaluated for those patients with glioblastoma [17].

\section{CONCLUSION}

Decisions regarding the treatment of GBM and other high-grade gliomas are interdisciplinary as a standard of care, requiring a high level of expert knowledge.

During this pandemic crisis, careful patient selection that balances the risks and benefits of treatment is paramount to optimize the care of patients with glioblastoma in this setting.

To alleviate disruption in patient care, we believe that interdisciplinary meetings should continue using healthcare technologies like video conferencing, conference calls or other digital methods to maintain expert discussion between disciplines.

Author contributions: All authors contributed equally. All authors confirmed the final article.

Conflict of Interest: None to Declare

Source of funding: No funding

\section{REFERENCES}

1. Guan $\mathrm{W}-\mathrm{J}$, Ni Z-Y, Hu Y, Liang $\mathrm{W}-\mathrm{H}$, et al. Clinical characteristics of coronavirus disease 2019 in China. N Engl J Med. 2020; 382(18): 1708-20. doi: 10.1056/NEJMoa2002032 PMid:32109013 PMCid: PMC7092819.

2. Liang W, Guan W, Chen R, Wang W, et al. Cancer patients in SARS-CoV-2 infection: A nationwide analysis in China. The Lancet. 2020; 21(3): 335-7. doi: 10.1016/S1470-2045(20)30096-6.

3. Liu K, Chen $\mathrm{Y}$, Lin R, Han K. Clinical features of COVID-19 in elderly patients: A comparison with young and middle-aged patients. J Infect. 2020; 80(6): e14-e18. doi: 10.1016/j.jinf.2020.03.005 PMid:32171866 PMCid:PMC7102640.

4. Brooke J, Jackson D. Older people and COVID-19: Isolation, risk and ageism. J Clin Nurs. 2020; 29(1314): 2044-6. doi: 10.1111/jocn.15274 PMid: 32239784 .

5. Stupp R, Mason WP, van den Bent MJ, Weller M, et al. Radiotherapy plus concomitant and adjuvant temozolomide for glioblastoma. N Engl J Med. 2005; 352(10): 987-96. doi: 10.1056/NEJMoa043330 PMid:15758009.
6. Weller M, van den Bent M, Tonn JC, Stupp R, et al. European Association for Neuro-Oncology (EANO) guideline on the diagnosis and treatment of adult astrocytic and oligodendroglial gliomas. Lancet Oncol. 2017; 18(6): e315-e329. doi: 10.1016/S1470-2045(17)30194-8 PMID: 28483413.

7. Chaichana KL, Jusue-Torres I, Lemos AM, Gokaslan A, et al. The butterfly effect on glioblastoma: is volumetric extent of resection more effective than biopsy for these tumors? J Neurooncol. 2014; 120(3): 625-34. doi: 10.1007/s11060-014-1597-9 PMid:25193022 PMCid:PMC4313925.

8. Chaichana KL, Jusue-Torres I, Navarro-Ramirez R, Raza SM, et al. Establishing percent resection and residual volume thresholds affecting survival and recurrence for patients with newly diagnosed intracranial glioblastoma. Neuro Oncol. 2014; 16(1): 113-22. doi: 10.1093/neuonc/not137 PMid: 24285550 PMCid:PMC3870832.

9. Sanai N, Polley $M-Y$, McDermott MW, Parsa AT, Berger MS. An extent of resection threshold for newly diagnosed glioblastomas. J Neurosurg. 2011; 115(1): 3-8. doi: 10.3171/2011.2.jns10998 PMid: 21417701.

10. Senft C, Bink A, Franz $K$, Vatter $H$, et al. Intraoperative MRI guidance and extent of resection in glioma surgery: a randomised, controlled trial. Lancet Oncol. 2011; 12(11): 9971003. doi: $10.1016 /$ S1470-2045(11)70196-6

11. Bernhardt D, Wick W, Weiss SE, Sahgal A, et al. Neuro-oncology Management During the COVID-19 Pandemic with a Focus on WHO Grade III and IV Gliomas. Neuro-Oncol. 2020; 22(7): 928-35. doi: 10.1093/neuonc/noaa113 PMid:32369601 PMCid: PMC7239150.

12. Núñez-Velasco S, Mercado-Pimentel R, RodríguezArias R. Letter to the Editor: Awake Craniotomy for Intracranial Gliomas During Coronavirus Disease 2019 Pandemic. World Neurosurg. 2020; 140: 4702. doi: 10.1016/j.wneu.2020.05.219 PMid: 32485243 PMCid:PMC7260566.

13. Chen Z-P. Glioma patients facing COVID-19 pandemic. Glioma. 2020; 3(1): 1 . doi: 10.4103/glioma.glioma_6_20 
14. Ramakrishna $R$, et al. Inpatient and outpatient case prioritization for patients with neurooncologic disease amid the COVID-19 pandemic: general guidance for neuro-oncology practitioners from the AANS/CNS Tumor Section and Society for Neuro-Oncology. J Neurooncol. 2020; 147(3): 5259. doi: 10.1007/s11060-020-03488-7 PMid: 32274630 PMCid:PMC7145274.

15. Wu S, Zheng $D$, Liu $Y$, Hu $D$, et al. Radiation Therapy Care During a Major Outbreak of COVID-19 in Wuhan. Adv Rad Oncol. 2020; 5(4): 531-3. doi: 10.1016/j.adro.2020.03.004 PMid: 32775770 PMCid:PMC7270882.
16. Hegi ME, Diserens A-C, Gorlia T, Hamou M-F, et al. MGMT gene silencing and benefit from temozolomide in glioblastoma. N Engl J Med. 2005; 352(10): 997-1003. doi: 10.1056/NEJMoa043331 PMid:15758010.

17. Al-Jabir A, et al. Impact of the coronavirus (COVID19) pandemic on surgical practice-Part 2 (surgical prioritisation). Int J Surg. 2020; 79: 233-48. doi: 10.1016/j.ijsu.2020.05.002 PMid:32413502 PMCid: PMC7217115.

18. Baba MA, et al. Risk of COVID-19 for Patients with Cancer: A Narrative Overview. European J Med Ed Te. 2020; 13(3): em2008. doi: 10.30935/ejmets/8257. 